\title{
Dublês do setor elétrico: Reflexões sobre identidade e trabalho terceirizado
}

The electrical sector's stuntmen: Reflections on identity and outsourced work Los dobles del sector eléctrico: Reflexiones sobre identidad y trabajo subcontratado

\author{
Laís Di Bella Castro RABELO \\ Marcelle La Guardia Lara de CASTRO \\ Julie Micheline Amaral SILVA \\ Universidade Federal de Minas Gerais, Belo Horizonte, MG, Brasil
}

Resumo

Partindo do pressuposto que o trabalho é fator estruturante da vida psíquica e social dos sujeitos, buscouse compreender a relação entre a construção identitária e o processo de terceirização do trabalho no setor elétrico de Minas Gerais. Para tanto, utilizou-se da associação de dados obtidos por meio de revisão bibliográfica e estudo de caso que contemplou entrevista em profundidade com um trabalhador terceirizado do setor. Verificou-se um cenário de precarização associado à vulnerabilidade da saúde e segurança dos trabalhadores, impactando diretamente na fragilização de sua identidade social. $\mathrm{O}$ trabalhador eletricitário entrevistado afirma se sentir um dublê, aquele que substitui o trabalhador do quadro próprio, mas em piores condições e sem o devido reconhecimento, assumindo o perigo da cena sem receber os créditos da atuação. Considerando que a precariedade como situação de trabalho é também uma condição de experiência, e que não há dinâmica separada entre o que o trabalhador experimenta e como ele se autoconstrói, concluiu-se que na ausência das condições básicas de saúde e segurança, os trabalhadores eletricitários terceirizados encontram-se expostos a riscos e fragilizados socialmente. A terceirização, como uma prática perversa de redução de custos do capital, tem ampliado os mecanismos de exploração, gerando uma objetividade adversa aos trabalhadores, o que acarreta subjetividades precarizadas. Por fim, evidencia-se a associação entre precariedade laboral e precariedade social, pois a precariedade do trabalho como experiência subjetiva impacta a construção de relações sociais, na dimensão de acesso aos direitos e da constituição de cidadania.

Palavras-chave:

Identidade social; trabalho; terceirização.

Abstract Assuming that work is a structuring part of the individual's psychic and social life, this article seeks to understand the relationship between identity construction and the work outsourcing process in the electrical sector of Minas Gerais. To this end, a combination of data obtained from both literature review and case study, which included an in-depth interview with an outsourced worker from the electrical sector, was used. A precarious situation associated with the vulnerability of workers' health and safety, with direct impacts on the fragility of their social identity, was observed. The electrician interviewed says he feels like a stunt double, who replaces himself in his own work scenario, but in worse conditions and without proper recognition, taking the risk of the scene without receiving the performance credits. Considering that precariousness as a work situation is also an experiential condition, and that there is no separate dynamic between what the employee experiences and how he constructs himself, it was concluded that by lacking basic health and safety conditions, outsourced electrical workers are at risk and socially vulnerable. Outsourcing as a perverted pragmatic reduction of capital costs has amplified the mechanisms of exploitation, generating an objectivity adverse to workers, which leads to precarious subjectivities. Finally, the association between work precariousness and social precariousness is made clear, since the precariousness of work as a subjective experience has impacts on the construction of social relations, on the scope of access to rights, and the constitution of citizenship.

Keywords:

Social identity; work; outsourcing. 
Partiendo de la suposición de que el trabajo es un factor estructurador de la vida psíquica y social de los sujetos, en este estudio se pretende comprender la relación entre la construcción de la identidad y el proceso de subcontratación del trabajo en el sector eléctrico de Minas Gerais. Para ello, se utilizó la asociación de datos obtenidos por medio de revisión bibliográfica y estudio de caso que tuvo en cuenta una meticulosa entrevista con un trabajador subcontratado del sector. Se verificó un escenario de precariedad asociado a la vulnerabilidad de la salud y seguridad de los trabajadores, el cual afecta directamente a la fragilidad de su identidad social. El trabajador electricista entrevistado dijo sentirse un doble, que reemplaza el trabajador de puesto fijo, pero en peores condiciones y sin el debido reconocimiento, asumiendo el riesgo de la escena sin recibir los créditos de la actuación. Considerando que la precariedad como situación de trabajo es también una condición de experiencia, y que no hay dinámica separada entre lo que el trabajador experimenta y cómo él se autoconstruye, se concluyó que, por defecto de las condiciones básicas de salud y seguridad, los trabajadores electricistas subcontratados están expuestos a riesgos y a la vulnerabilidad social. La subcontratación, como una pragmática perversa de disminución de costos del capital, ha ampliado los mecanismos de explotación, generando una objetividad adversa a los trabajadores, lo que conlleva subjetividades precarias. Por fin, se destaca la asociación entre precariedad laboral y precariedad social, pues la precariedad del trabajo, como una experiencia subjetiva, causa impacto en la construcción de relaciones sociales, en la dimensión de acceso a los derechos y de la constitución de la ciudadanía.

Palabras-clave:

Identidad social; trabajo; subcontratación.

A terceirização é um processo de externalização das relações trabalhistas, fruto da lógica de flexibilização do trabalho no âmbito do capitalismo neoliberal, que tem se solidificado a partir da reestruturação produtiva ocorrida com maior intensidade a partir do final do século XX. Essa forma de vínculo empregatício, que busca status constitucional no Brasil, estabelece novas relações de trabalho que têm impacto direto na realidade em que os sujeitos produzem a objetivação de sua subjetividade e, logo, constroem sua identidade social.

Como situação conjuntural persistente amplamente associada a uma precarização das condições de trabalho e à violação das conquistas sociais trabalhistas (Coura, 2011; Coutinho, 2015; Franco, Druck, \& SeligmannSilva, 2010), a terceirização está diretamente relacionada à atividade subjetiva (Gennari \&Albuquerque, 2013), da construção de sujeitos sociais (Thompson, 1981). Assim, faz-se necessário compreender os modos de subjetivação que decorrem dessa realidade objetiva, principalmente na esfera da Psicologia do Trabalho, em que a dimensão subjetiva do mundo do labor, em constante transformação, é tomada como matéria fundamental.

A partir dessa perspectiva, ressalta-se a importância de compreender a subjetividade dos trabalhadores do setor elétrico em Minas Gerais, no qual a subcontratação como estratégia competitiva, que tem como objetivo reduzir os custos da produção, tem se ampliado em larga escala. A Companhia Energética de Minas Gerais (CEMIG), especificamente, tem reduzido seu quadro efetivo de forma crescente, de modo que, em 2013, os terceirizados já representavam 68,51\% da força de trabalho da empresa (Fundação Comitê de Gestão Empresarial [FUNCOGE], 2013).

Considerando que as transformações dos modos de produção, como a flexibilização dos vínculos empregatícios decorrente do processo de terceirização, promovem significativas consequências para a constituição do ser, visto que a identidade social refere-se à processualidade dialética das dimensões subjetivas e objetivas, em que o trabalho se apresenta como categoria de grande expressividade (Jacques, 1996), objetiva-se propor reflexões sobre identidade e trabalho terceirizado. Nessa conjuntura de intensa terceirização do trabalho no setor elétrico, questiona-se: como a terceirização afeta a produção de identidade social dos trabalhadores eletricitários?

Parte-se do pressuposto de que o trabalho é fator estruturante da vida psíquica e social dos sujeitos (Antunes, 2000; Clot, 2010; Gaulejac, 2007) e peça central para entender a constituição humana, o que o torna uma importante categoria analítica do mundo social (Organista, 2006). É, portanto, base essencial para a construção da identidade (Lima, 2008) e o meio pelo qual o homem dialoga com seu tempo, o que permite a criação de si, ao mesmo tempo em que cria o meio objetivo em que vive. Desse modo, ao agir sobre o mundo de maneira intencional, o homem transforma a realidade e imprime sua marca em um processo irreversível, no qual sujeito e mundo jamais saem iguais.

O trabalho não é apenas uma imposição, uma obrigação, uma injunção que nos é feita. É, igualmente, uma oportunidade que nos é dada de construção de nós mesmos. O trabalho funciona como um operador de 
identidade, como um meio de construção de nós mesmos, de nossa identidade, um operador central do desenvolvimento da pessoa. (Jobert, 2014, p. 25)

Compreender o processo de individuação, portanto, significa adentrar o conjunto das formas de sociabilidade que darão a base estrutural para elucidar a individualidade como a síntese máxima da existência social (Chasin, 2001), assim como se interpreta a partir de Marx e Engels, na Ideologia Alemã, "o homem é o que faz e como faz" (Chasin, 2001, p. 55).

\section{MÉTODO}

\section{Participante}

A entrevista em profundidade foi realizada com um trabalhador terceirizado do setor elétrico de Minas Gerais, aqui identificado pelo nome fictício de Paulo, que tem 40 anos e ensino fundamental incompleto. Os objetivos e métodos foram devidamente informados ao sujeito participante, que assentiu de forma livre e esclarecida sobre a utilização da sua entrevista para produção de pesquisa científica. O trabalho em tela frisou o cuidado com a dignidade humana e a autonomia do participante, bem como a proteção de seus dados, impedindo sua identificação. Além disso, garantiu-se que a pesquisa não traria a ele quaisquer malefícios.

\section{Procedimentos de coleta de dados}

A metodologia desta pesquisa é essencialmente qualitativa, buscando a exploração de dados empíricos revelados em boletins sindicais dos eletricitários que denunciam as condições de trabalho da categoria, de estatísticas de acidentes e de formas contratuais de trabalho oriundas das principais fontes de dados do setor e de estudo de caso realizado por meio de entrevista em profundidade com o trabalhador terceirizado. Desse modo, dados secundários e primários permitiram a construção de um material para análise que engloba, em um panorama mais amplo, números relativos ao contexto brasileiro da saúde e da segurança no setor e afunilase em dados empíricos relativos aos casos estudados de eletricistas terceirizados do estado de Minas Gerais. A escolha metodológica deve-se à riqueza da investigação de dados quantitativos e qualitativos que, juntos, darão maior embasamento às reflexões sobre identidade e trabalho terceirizado pretendidas.

A revisão bibliográfica sobre a saúde e a segurança dos eletricitários, em especial dos trabalhadores de empreiteiras, foi realizada nas principais bases de dados que oferecem um estado da arte para a compreensão do que tem sido estudado no Brasil sobre o tema, destacando aqui os Periódicos CAPES, SciELO e livros publicados sobre o assunto. Também foram investigados dados estatísticos e empíricos nas seguintes fontes: Fundação Comitê de Gestão Empresarial (FUNCOGE), Central Única dos Trabalhadores (CUT), informações de dados internos fornecidos às autoras e Boletins publicados pelo Sindicato Intermunicipal dos Trabalhadores na Indústria Energética de Minas Gerais (SINDIELETRO-MG) no jornal sindical Chave Geral. A escolha dessas bases ocorreu devido à relevância dos estudos sindicais que historicamente buscam acompanhar as condições de trabalho e da dimensão que a FUNCOGE, especialmente, tem hoje dos estudos estatísticos do setor, abrangendo 67 empresas públicas e privadas responsáveis por cerca de $90 \%$ de toda energia gerada, transmitida e distribuída no país.

Para compreender a complexidade dos dados estatísticos e fazer uma análise que atravesse o contexto sócio-histórico do trabalhador terceirizado e a construção de sua identidade, foi realizado estudo de caso com a preocupação de se entender o que o singular sugere a respeito do todo (Ventura, 2007). É desse modo que a análise detalhada de um caso individual procura abarcar as dinâmicas processuais intrínsecas à própria vida, imersa em um cenário político, econômico, social e cultural que também se metamorfoseia com essa imersão. Desse modo, para alcançar maior profundidade e complexidade da construção identitária, é preciso entender

a representatividade do indivíduo como uma unidade complexa da qual surgem os elementos constitutivos da subjetividade tanto individual quanto social dentro da diversidade de sua constituição única. Por isso o estudo de caso não é uma opção metodológica, como no método clínico, mas uma exigência epistemológica para o conhecimento da subjetividade. Embora possa haver objeção quanto à impossibilidade de generalização, o papel da singularidade, nesse planejamento epistemológico, é um dos elementos essenciais da definição de seu caráter qualitativo, uma vez que a análise de casos volta-se a processos únicos de interpretação. (Palassi \& Paula, 2014, p.161) 
O estudo de caso desdobrou-se a partir da produção de um parecer técnico para fins judiciais, em que uma das autoras atuou como assistente técnica de um trabalhador terceirizado do setor elétrico, que pleiteia indenização na Justiça do Trabalho devido a acidente decorrente de choque elétrico. A produção do parecer contemplou entrevista em profundidade, realizada em janeiro de 2015, com duração de três horas, em que se buscou compreender os impactos psicossociais do acidente de trabalho. A temática da identidade do trabalhador terceirizado ${ }^{2}$ no setor elétrico atravessou o discurso do entrevistado sem que houvesse uma intencionalidade $a$ priori da entrevistadora acerca dessa questão.

\section{Procedimentos de análise de dados}

Os dados foram analisados a partir de uma perspectiva qualitativa, de forma a atrelar o panorama do processo de terceirização à formação da identidade do profissional terceirizado do setor elétrico de Minas Gerais, na perspectiva da análise de discurso de linha francesa (Pêcheux, 2002). Assim, a produção de sentidos ao discurso do trabalhador foi realizada na articulação entre a fala e seu contexto sócio-histórico, de forma que a linguagem é compreendida como a materialidade do texto que gera indícios de uma memória coletiva constituída socialmente e marcada pela ideologia das condições de produção em que se encontra. Desse modo, a análise dos dados não se propôs a uma tradução do que foi dito pelo trabalhador, mas a uma análise vertical a partir de recortes do discurso que possibilitaram uma leitura interpretativa acerca da produção identitária pelo trabalho, incluindo sua dimensão política e valorizando a ancoragem da fala do sujeito à história (Gadet \& Hak, 1993; Pêcheux, 2002).

\section{RESULTADOS}

\section{Panorama do setor}

$\mathrm{O}$ crescimento da terceirização no setor elétrico brasileiro evidencia a lógica valorativa que permeia os atuais modos de contratação da força de trabalho, que visa reduzir custos ao mesmo tempo em que expõe os trabalhadores a uma sinergia de fatores que potencializam os riscos no trabalho. Em 2004, o número de profissionais do quadro próprio no setor era de 96.579, enquanto os terceirizados somavam 76.972; em 2013, o quadro próprio era de 105.962 e os terceirizados chegaram a 130.833 (FUNCOGE, 2013). Desse modo, enquanto o aumento do primeiro foi de $9,72 \%$ no período, os terceirizados aumentaram $69,97 \%$, o que reafirma os traços do crescimento do setor elétrico brasileiro pautado no afrouxamento dos vínculos empregatícios do trabalhador.

A contratação de força de trabalho terceirizada nesse setor cerceia a saúde e a segurança no trabalho devido à diminuição dos benefícios sociais, aos salários mais baixos, à ausência de equipamentos de proteção, ao trabalho sem registro em carteira, à perda da representação sindical (Marcelino \& Cavalcante, 2012; Martinez \& Latorre, 2008) e às demais condições que reduzem as margens de manobra do trabalhador na execução do serviço e potencializam os riscos inerentes a essa atividade perigosa, o que culmina em altos índices de adoecimentos e acidentes.

Em análise de dados coletados entre 2003 e 2012 sobre o setor elétrico brasileiro, pela FUNCOGE (2013) verificou-se que a taxa média anual de acidentes fatais típicos de todos os trabalhadores brasileiros foi calculada em 7 por 100.000; entre trabalhadores do quadro próprio das empresas do setor elétrico a taxa chegou a 12,37 por 100.000. A situação é ainda muito mais grave quando são considerados os dados de empregados das contratadas, ou seja, para a força de trabalho total do setor elétrico brasileiro a taxa foi de 36,77 por 100.000. Conclui-se então que o número de acidentes fatais no setor elétrico, considerando terceirizados e quadro próprio, neste período, é 5,25 vezes maior quando comparado às demais atividades produtivas brasileiras, ou seja, um setor de alto risco que é agravado pela terceirização. Dados coletados entre 2001 e 2013, também pela FUNCOGE (2013) revelam 183 acidentes fatais entre empregados do quadro próprio e 748 mortes no quadro das contratadas, o que resulta em um número 4,09 vezes maior entre essas empresas.

De acordo com dados fornecidos às autoras em 2015 pelo SINDIELETRO-MG, em Minas Gerais não houve registros de acidentes fatais com trabalhadores do quadro próprio da concessionária de energia do estado em 2014, entretanto, foram notificados quatro acidentes fatais com funcionários terceirizados. Ainda com base

O trabalhador autorizou a divulgação de seus dados, bem como as transcrições literais de falas, para fins de produção de documentos científicos, preservando-se seu anonimato. 
em dados fornecidos pela entidade, no período de janeiro a julho de 2015, foram registrados quatro acidentes fatais com funcionários de empreiteiras. Em contrapartida, ressalta-se a ausência de acidentes dessa magnitude com trabalhadores do quadro próprio da empregadora. Além disso, considerando o mesmo período, o Sindicato registrou que $81,33 \%$ do total de acidentes registrados pela empresa eram oriundos do quadro terceirizado.

Ressalta-se que esse cenário torna-se ainda mais alarmante quando se considera a subnotificação frequente de acidentes de trabalho. Muitos deixam de ser registrados por meio do Comunicação de Acidente de Trabalho (CAT), privando as entidades públicas de reconhecerem essa realidade, bem como usurpando o trabalhador dos próprios direitos legais. Domingos (2005) ressalta que em estudo de acidentes fatais realizado no setor elétrico cearense, ocorridos entre 1994 e 2004, dos 36 acidentes fatais, apenas 13 emitiram CAT. Em Minas Gerais, de acordo com o SINDIELETRO-MG, muitos acidentes, principalmente de empresas terceirizadas, são encobertos, e, muitas vezes, camuflados pela readequação de trabalhadores, que continuam exercendo atividades laborais adaptadas à sua nova condição pós-acidente.

As altas taxas de acidentes e fatalidades estão intrinsicamente relacionadas à precariedade que a terceirização promove no setor. Em Minas Gerais, esse panorama é caracterizado pela intensificação do trabalho, pela flexibilização dos vínculos empregatícios, pela fragilização das relações laborais e pela debilidade das condições físicas e sociais de trabalho. Os elementos empíricos que demonstram a precariedade do setor foram encontrados nos boletins do jornal sindical do SINDIELETRO-MG ${ }^{3}$, Chave Geral, e no dossiê apresentado pela CUT (2014), os quais denunciam as extensas jornadas de trabalho; as pressões temporais e as metas abusivas atreladas aos baixos salários; a redução do quadro de funcionários; o excesso de horas extras; a ausência de pausas suficientes para refeições e descansos; a ausência de folga e férias regulares relacionadas à grande rotatividade de contrato de trabalho; a inexistência de adicional de periculosidade, vale transporte, vale alimentação e plano de saúde; a escassez de manutenção das ferramentas, dos uniformes e dos equipamentos de proteção individual (EPI) e coletivos (EPC); o treinamento insuficiente e inadequado; as condições precárias dos alojamentos relacionadas à presença de esgoto a céu aberto, falta de água potável e alimentos armazenados em locais insalubres; e as altas taxas de acidentes mutilantes e fatais.

Os elevados números de acidentes e adoecimentos encontrados no setor colocam em questão as atuais formas de gestão da saúde e da segurança dentro e fora das concessionárias. O quadro próprio, embora apresente índices de acidentes mais baixos em relação aos terceirizados, também está exposto a essa potencialização dos riscos e tem altos números quando comparados aos demais setores da economia brasileira. Além disso, a redução das contratações no quadro próprio pode implicar na intensificação do trabalho e na sobrecarga física e mental, prejudicando substancialmente a gestão dos riscos, que está sempre além da normatividade prescrita pelos saberes especializados em saúde e segurança no trabalho, pois é, sobretudo, resultado da aglutinação dos saberes construídos historicamente, por meio da experiência individual e coletiva (Echternacht, 2008).

\section{Estudo de caso}

No período de 2003 a 2012, Paulo trabalhou como eletricitário na manutenção de rede elétrica em nove empreiteiras. Foi desligado de sua função e aposentado, devido a um acidente de trabalho decorrente de choque elétrico, no qual perdeu os dois antebraços e parte da perna esquerda, impossibilitando-o de exercer novamente sua função, bem como quaisquer outras atividades laborais.

Paulo afirma que a conjuntura de trabalho dos eletricitários terceirizados é crítica e precária, sem condições adequadas de segurança, alimentação e assistência à saúde. Durante seu trabalho como eletricitário terceirizado, sofria pressão temporal e por produção, tratamento desrespeitoso por parte de seus encarregados, riscos cotidianos de acidentes, ausência de treinamento e equipamentos adequados, não usufruía adequadamente dos intervalos para as refeições e descanso e vivenciava jornadas de trabalho prolongadas com excesso de horas extras. A desresponsabilização da contratante acerca da subcontratação de sua mão de obra está relacionada aos riscos cotidianos vivenciados pelos contratados das empreiteiras:

É muita coisa que acontece no dia a dia em uma empreiteira...bié [eletricitário] de empreiteira... é absurdo, os cara é artista, são dublê mesmo. Bié [eletricitário] de empreiteira eu costumo falar assim: é uma praga que a bomba atômica vai ser difícil matar porque o que os cara passa durante o dia e sobrevive, é muita coisa.

\footnotetext{
Boletins do Jornal Sindical Chave Geral, publicados entre janeiro de 2012 e março de 2015 (edições 696 a 773), disponíveis em: http:// sindieletromg.org.br/.
} 
Cề tem a linha de vida? Tenho. Mas não tem ninguém [da contratante] olhando pra você ali 24 horas olhando para aquela equipe pra fazer o encarregado entender que cê tem que usar, num é... Porque pra mim, num importa eu gastar 40 minutos pra subir num poste, eu não trabalho por produção, a empresa [contratante] que... ela que força. Por quê?? Porque ela trabalha por produção.

A competência profissional dos terceirizados é desenvolvida em meio a condições precárias, que exigem do trabalhador regulações ${ }^{4}$ muitas vezes incompatíveis com a própria condição humana para conseguir gerir a carência de recursos materiais e organizacionais. Essa precariedade objetiva, marcada pela falta de ferramentas e estruturas adequadas para o exercício da atividade, soma-se ao coletivo fragilizado em que o encarregado, profissional responsável por gerenciar as condições seguras de trabalho, pressiona por produção, muitas vezes negligenciando a normatividade em prol da produtividade acordada no contrato feito com a concessionária.

É nessa interação entre os aspectos objetivos que circundam o cotidiano de trabalho e os aspectos subjetivos do trabalhador, que o medo se manifesta como um sentimento que evidencia a ameaça física, psíquica e social presentes no meio, deixando de ser um sinal de perigo e tornando-se um traço constitutivo do próprio trabalho:

Cê tinha que trabalhar numa rede, mesmo aterrada, debaixo de uma transmissão. E o medo de um fio daquele, é claro que não vai cair, mas cê tinha medo daquilo cair em cima. Então é um serviço que cê trabalha com muito medo.

Desse cenário emerge a construção de uma identidade mergulhada na fragilização das possibilidades de gestão da própria vida, em que o medo torna-se um ímpeto que circunda as ações no trabalho. Ao mesmo tempo em que a atuação é exercida com mérito, não há garantias do reconhecimento social, posto que ao trabalho realizado pelas empreiteiras resta o anonimato. A atividade, os riscos e o sofrimento do eletricitário terceirizado são invisibilizados. Para Paulo, o trabalhador eletricitário terceirizado é aquele que substitui o trabalhador do quadro próprio, mas em piores condições e sem o devido reconhecimento, como dublês, assumindo o perigo da cena, mas não recebendo os créditos da atuação:

As condiçôes de trabalho da empreiteira écrítico demais, na verdade a gente (...) vivia no anonimato, nós era o dublê.

$A$ [empresa contratante] hoje não faz nada, quem corre o risco somos nós.

Vai no mato e olha pra uma rede elétrica, tem lugar que cê imagina, como é que esse fio passou aqui? Nós! Pôs aquele fio nas costas e como um bocado de formiguinh a foi trabalhar atravessando córrego, mata, pulando buraco, até chegar do outro lado e aquela rede tá lá levando energia pro mundo todo. O 'Luz para Todos' [Programa do Ministério de Minas e Energia que visa ampliar a distribuição de energia elétrica no Brasil] é uma felicidade pra todo mundo, mas o tanto que nós sofreu.

A multiplicidade de riscos e a invisibilidade do trabalhador eletricitário terceirizado se retroalimentam. Ao mesmo tempo em que estão escondidos dos holofotes, são importantes artistas para a manutenção da energia para os consumidores, correndo riscos cotidianamente no exercício da atividade, mas cuja identidade de quem de fato realiza aquele trabalho é desconhecida pela sociedade. Essa ausência de reconhecimento e, consequentemente, do fornecimento de um panorama adequado de saúde e segurança, afetam a construção da identidade social desses sujeitos.

Exposta a riscos e fragilizada socialmente, a categoria é percebida por Paulo como substituta anônima dos trabalhadores do quadro próprio. Ele ressalta a dificuldade de construção de uma identidade social diante do anonimato ao qual é submetido o eletricitário terceirizado:

Empreiteira é um trem esquisito e outra coisa, um esquisito que não existe, nós não existe, nós existe pra [empresa contratante], a terceirizada. Mas o mundo, vou falar Minas Gerais, não sabe o que é uma empreiteira, porque aqui

4 O conceito de regulação na ergonomia refere-se à capacidade desenvolvida pelo operador de gerenciar as condições internas e externas da atividade para evitar repercussões negativas em seu corpo e para alcançar os objetivos fixados pela organização (Falzon, 2007). 
é a [empresa contratante], uai. Nós somos dublê. (...) nós é que nem o sombra do Silvio Santos, só sabe que existe o sombra, mas quem é o sombra? Então nós não existe.

Então as condiçôes de trabalho da empreiteira é critico demais. A verdade a gente veste, todo mundo... Hoje, o 'Luz para Todos', ninguém sabe, que gostava de falar com os cara que nós vivia no anonimato, nós era o dublê da [empresa contratante]. É porque quando nós faz uma rede, o 'Luz para Todos', se ver a propaganda lá, aparece um cara com a camisa da [contratante] e uma caminhonete da [contratante], nunca aparece um cara da empreiteira (...) é nós que faz, na verdade (...) a [empresa contratante] hoje ela não faz nada, quem corre o risco de tudo somos nós, entendeu?

Eu sei que todo trabalbador passa por muita coisa, mas nós trabalba no mato, ninguém nos vê. Só no anonimato, ninguém conhece empreiteira. Se nós vai lá trocar um poste e pergunta pro fazendeiro quem trocou o poste? Ele fala: ah, a [empresa contratante]. Agora se cê vai lá e o poste quebrou, a [contratante] fala: foi a empreiteira. (...) se o serviço saiu bem foi a [contratante].

As reflexões de Paulo evidenciam a invisibilidade dos trabalhadores terceirizados perante a sociedade. A supressão da individualidade não advém com a homogeneização dos indivíduos, mas com a efemeridade de sua posição no trabalho: não é mais aquele que faz, mas um sósia, a projeção daquele que efetivamente aparece no círculo social.

\section{DISCUSSÃO}

A precariedade como condição de trabalho é também uma condição de experiência (Cingolani, 2005). Experienciar o meio não é só sentir o que é percebido, mas também o que se faz com aquilo que é sentido, ou seja, viver o momento com base na história que se carrega, no passado que ficou, mas ainda está presente, impresso em nossa subjetividade. A experiência, tomada como categoria explicativa, a partir do que propõe Thompson (1981), possibilita compreender o caráter vivido de uma realidade social, que é constitutiva dos sujeitos nela inserida, principalmente acerca de como o modo de produção capitalista exerce pressões sociais e culturais (Bacelar, 2014; Minella, 2013). A experiência, entendida como a relação dialética entre o sujeito e os elementos da realidade que o cercam, exalta a relevância da configuração subjetiva do mundo sensível (Bacelar, 2014).

Como ser social, não há dinâmica separada entre o que o trabalhador experimenta e como ele se autoconstrói. Os eletricitários terceirizados estão submetidos à rentabilização de sua força de trabalho, reduzidos a sujeitos descartáveis (Heloani, 2015). Não dignos das condições básicas de saúde e segurança, encontram-se expostos a riscos e fragilizados socialmente.

Considerando o trabalho elemento estruturante da identidade dos sujeitos, configura-se, então, uma situação paradoxal: como se autoconstruir quando a objetivação da subjetividade está atravessada por um cenário de precarização? A formação da identidade social está intrinsicamente ligada ao olhar do outro, ao que se pode suscitar no mundo de forma a tornar os indivíduos singulares (Heloani, 2015). Assim como aponta a perspectiva de Alain Touraine, ser sujeito significa almejar ser ator, atuar de forma a modificar seu meio social, mais do que ser determinado por ele, por meio de um processo de alteridade, que não implica subjugação, mas a busca do reconhecimento de si pelo outro (Gadea \& Scherer-Warren, 2005). Entretanto, o trabalhador terceirizado, imerso na invisibilidade, na posição de "dublê" dos trabalhadores de quadro próprio, tem o esfacelamento de sua identidade e reconhecimento social, pois não alcança o papel do ator.

Ser ator convoca a competência no trabalho, traduzida como dinâmica vital da construção de si, pois o reconhecimento no trabalho como busca permanente é o que nos conduz a submeter nosso agir ao julgamento do outro (Jobert, 2014). Mas será possível o agir competente na atrocidade da precarização? Observando a amputação das condições mínimas de vida e de trabalho no setor elétrico, consequentes dos processos de terceirização, subjugam-se esses trabalhadores a uma condição marginal, que delimita as possibilidades de inserção em um meio material e social de sobrevivência. A construção identitária, dessa forma, é construída na precariedade engendrada pelo meio, ou seja, na escassez de recursos para a execução do trabalho e, consequentemente, na carência de meios que promovam a criação do próprio homem. Assim, trabalhar na insuficiência, 
na debilidade e na insegurança coloca o trabalhador em conflito com sua própria identidade, tanto em nível individual, quanto social. Ao "dublê", mesmo que supere a escassez de recursos e alcance a competência técnica, como comumente fazem os eletricitários terceirizados, cabe a invisibilidade. A impossibilidade do reconhecimento social impõe ao trabalhar terceirizado um papel de artista sem mérito, uma identidade produzida à margem, à sombra do trabalhador do quadro próprio.

Assim, podemos dizer que não existe uma separação entre o mundo objetivo do emprego e o mundo subjetivo do reconhecimento da existência do indivíduo, pois esses mundos se materializam na essência de uma relação dual, na qual a singularidade do fórum interior individual encontra ou não significação no espaço ampliado do mundo do emprego. (Heloani, 2015, p. 479)

A terceirização como uma prática perversa da lógica destrutiva do capital tem ampliado os mecanismos de exploração e sujeição dos trabalhadores, gerando uma objetividade precarizada que acarreta subjetividades precarizadas (Antunes, 2014). Essa realidade neoliberal produz uma materialidade adversa aos trabalhadores, um solo social que constrange as possibilidades de construção de subjetividades autênticas (Antunes \& Alves, 2004). Dessa forma, a precarização do trabalho está relacionada a processos de exclusão, principalmente no contexto do capitalismo flexível, dificultando a construção de uma imagem valorizada e sólida de si e impossibilitando a estruturação de identidades coletivas e políticas estáveis e valorizadas (Barros \& Nogueira, 2007).

[...] falar de precariedade não é apenas abordar os fenômenos sociais ligados às transformações no mundo do trabalho e emprego, aqueles que colocam acento sobre as populações mais atingidas e se abrem às questões relativas à proteção social e saúde e segurança no trabalho. É também, e mais amplamente, traduzir a emergência dos processos sociais que culminam na evolução das formas de estruturação dos espaços produtivos e das formas de regulação social que aí se articulam. Trata-se de uma transformação das regras, das normas, dos valores associados ao trabalho. (Saint-Martin, 2008, p.1, tradução livre)

A partir dessa perspectiva, a terceirização, nos moldes atuais do setor elétrico, pode ser caracterizada como uma forma de flexibilização operacional, que fragiliza a construção da identidade ao subjugar os trabalhadores a um meio físico e social precário e incapaz de fornecer condições e valores sólidos para a emancipação humana. Destarte, evidencia-se a associação entre precariedade laboral e precariedade social. A precariedade do trabalho como experiência subjetiva impacta a construção de relações sociais, na dimensão de acesso aos direitos e da constituição de cidadania. Há, assim, uma dimensão de vulnerabilidade associada aos trabalhadores submetidos à precariedade da terceirização, decorrente, inclusive, da limitação do papel regulador do Estado sobre esse processo neoliberal, que desampara os trabalhadores de proteção social (Barros, 2015; Gennari \& Albuquerque, 2013), ainda acrescida da escassez da representação sindical. Nesse sentido, a imposição de relações de trabalho precárias deve ser compreendida como violação de direitos, principalmente no que diz respeito ao artigo XXIII da Declaração Universal dos Direitos Humanos (Organização das Nações Unidas [ONU], 2009), que enfatiza a garantia de condições justas e favoráveis de trabalho que assegurem ao trabalhador uma existência compatível com a dignidade humana.

As mutações no mundo do trabalho atingem as formas de contratação e reduzem o proletariado estável, originando o novo proletariado (Antunes, 2000), submetido à precariedade social, uma classe negada no capitalismo contemporâneo que se prolifera em várias partes do mundo, atingindo países desenvolvidos, em vias de desenvolvimento e subdesenvolvidos. As condições precárias da estrutura sociotécnica engendrada pelo contexto da terceirização evidenciam a lacuna na lógica valorativa dos processos produtivos, que negligenciam as possibilidades de construção e gestão da saúde e segurança do trabalho, como se tais dimensões não pertencessem aos critérios de eficiência (Echternacht, 2008). Ora, se historicamente os processos de produção se relacionam aos modos de viver e adoecer no trabalho, é preciso vencer a dicotomia moderna que impõe condições arcaicas não condizentes com os padrões e conhecimentos científicos e técnicos alcançados na atualidade. As escolhas organizacionais refletem os princípios que permeiam a cultura e a economia, incidindo diretamente na construção da subjetividade, pois é por meio da identificação do indivíduo com aquilo que faz, edificando mutuamente o seu meio e a si próprio, que o permite criar novas formas de se posicionar no mundo e construir sua identidade. 
Ao apresentar os impactos psicossociais da terceirização e sua relação com a construção identitária do eletricitário, oferecemos um primeiro passo para aprofundar a temática e refletir sobre indagações propostas pela atuais práticas organizacionais. Tendo em vista a relevância política, social e econômica da eletricidade para o desenvolvimento do país, as implicações dos estudos sobre a saúde e a segurança dos eletricitários vão além de questões limitadas aos muros das empresas, atingindo, assim, toda a sociedade que usufrui e necessita dos serviços prestados com qualidade e eficiência.

Desse modo, lançar bases para compreender como a identidade é arquitetada e moldada no contexto de precarização do trabalho terceirizado no setor elétrico torna-se essencial, sobretudo devido à carência desses estudos na área de Psicologia do Trabalho. A revisão da literatura mostrou a restrição de pesquisas no campo, em especial sobre a construção identitária no trabalho terceirizado nesse setor, o que evidencia a atualidade do tema, que deve ser aprofundado e melhor analisado para lograr intervenções que melhorem as condições laborais e de vida desses trabalhadores.

Por fim, é importante destacar as limitações circunscritas a este estudo. A metodologia qualitativa centrada em único caso pode restringir a generalização, mas proporciona um nível profundo de análise que permite elucidar diferentes fatores pessoais e sociais envolvidos na construção da identidade no trabalho. A análise de discurso, nesse sentido, não pretende apreender a forma e o conteúdo do que foi dito, mas os efeitos de sentido que a interpretação do pesquisador medeia (Caregnato \& Mutti, 2006). Embora a interpretação do pesquisador seja passível de equívoco, pois carrega o olhar do outro e, portanto, de uma realidade diferente da do próprio sujeito, ela instiga um processo de reflexão mútua acerca da experiência. A atribuição de significados e sentidos pode ser limitada, mesmo que a interpretação pareça clara. Dessa maneira, o estudo está entremeado por contradições ao passo que traz importantes contribuições para o campo.

\section{REFERÊNCIAS}

Antunes, R. (2000). Os sentidos do trabalho: Ensaio sobre a afirmação e a negação do trabalho. São Paulo: Boitempo Editorial.

Antunes, R. (2014, agosto). Conferência de abertura. In $1^{\circ}$ Seminário Internacional de Análise e Prevenção de Acidentes do Trabalho. Seminário conduzido na Faculdade de Saúde Pública da USP e Faculdade de Medicina da UNESP, São Paulo,SP.

Antunes, R., \& Alves, G. (2004). As mutações no mundo do trabalho na era da mundialização do capital. Educação \& Sociedade, 25(87), 335-351. doi:10.1590/S0101-73302004000200003.

Bacelar, R. (2014). "Nem só de mineração vive o Mato Dentro": A experiência de jovens em território de conflito socioambiental (Tese de doutorado). Recuperado de https://conflitosambientaismg.lcc.ufmg.br/wp-content/uploads/2015/08/TesePROSDOCIMI-Rafael.-Nem-s\%C3\%B3-de-minera\%C3\%A7\%C3\%A3o-vive-o-MatoDentro.pdf

Barros, V. (2015). Trabalho e populações especiais. In P. Bendassolli \& J. Borges-Andrade (Orgs.), Dicionário de psicologia do trabalho e das organizações (pp. 649-657). São Paulo: Casa do Psicólogo.

Barros, V., \& Nogueira, M. (2007). Identidade e trabalho: Reflexões a partir de contextos precarizados e excludentes. Educação \& Tecnologia, 12(3), 10-12.

Boletins informativos do SINDIELETRO/MG. (2012, 2015; janeiro/março). Jornal Sindical Chave Geral. Recuperado de http:// sindieletromg.org.br/.

Caregnato, R. C., \& Mutti, R. (2006). Pesquisa qualitativa: Análise de discurso versus análise de conteúdo. Revista Texto Contexto Enfermagem, 15(4), 679-84.

Chasin, J. (2001). Rota e prospectiva de um projeto marxista. Ensaios Ad Hominem, 4, 1-41.

Cingolani, P. (2005). La precarité. Paris: Presses Universitaires de France - PUF.

Clot, Y. (2010). Trabalho e poder de agir. Belo Horizonte: Fabrefactum.

Coura, S. B. C. (2011). O capitalismo contemporâneo e suas transformações: O impacto da terceirização trabalhista. Revista do Tribunal Regional do Trabalho - 3를 Região, 53(83), 165-196.

Coutinho, G. F. (2015). Terceirização: Máquina de moer gente trabalhadora. São Paulo: LTr Editora.

Central Única dos Trabalhadores. (2014). Terceirização e desenvolvimento: Uma conta que não fecha. DIEESE/CUT: São Paulo.

Domingos, E. T. C. (2005). Acidentes do trabalho fatais no setor elétrico do Ceará: Características dos óbitos e circunstâncias dos acidentes ocorridos no período de 1994 a 2004 (Dissertação de mestrado). Recuperado de http://www.repositorio.ufc. $\mathrm{br} /$ handle/riufc/1026 
Echternacht, E. (2008). Atividade humana e gestão da saúde no trabalho: Elementos para a reflexão a partir da abordagem ergológica. Revista Laboreal, 4(1), 46-55.

Falzon, P. (2007). Natureza, objetivos e conhecimentos da ergonomia. In P. Falzon (Ed.), Ergonomia (pp. 3-19). São Paulo: Editora Blucher.

Franco, T., Druck, G., \& Seligmann-Silva, E. (2010). As novas relações de trabalho, o desgaste mental do trabalhador e os transtornos mentais no trabalho precarizado. Revista Brasileira de Saúde Ocupacional, 35(122), 229-248. doi:10.1590/ S0303-76572010000200006.

Fundação Comitê de Gestão Empresarial (2013). Relatório de estatísticas de acidentes no setor elétrico brasileiro. Rio de Janeiro: FUNCOGE.

Gadea, C., \& Scherer-Warren, I. (2005). A contribuição de Alain Touraine para o debate sobre sujeito e democracia latinoamericanos. Revista de Sociologia e Política, 25, 39-45. doi:10.1590/s0104-44782005000200005.

Gadet, F., \& Hak, T. (1993). Por uma análise automática do discurso: Uma introdução à obra de Michel Pêcheux (2a ed.). Campinas: Ed. Unicamp.

Gaulejac, V. (2007). A gestão como doença social: Ideologia, poder gerencialista e fragmentação social (2a ed.). Aparecida: Ideias \& Letras.

Gennari, A., \& Albuquerque, C. (2013, julho). Precarização do trabalho no Brasil: Mapeamento das configurações sociais, econômicas e políticas e impactos nas condições de vida dos trabalhadores e famílias. In VII Congresso Latino-americano de Estudos do Trabalho (ALAST). O Trabalho no Século XXI. Mudanças, impactos e perspectivas. Congresso realizado na Cidade Universitária da USP, São Paulo, SP.

Heloani, J. (2015). Novas formas de trabalho na contemporaneidade. In P. Bendassolli \& J. Borges-Andrade (Orgs.), Dicionário de psicologia do trabalho e das organizações (pp. 473-481). São Paulo: Casa do Psicólogo.

Jacques, M. D. G. C. (1996). Identidade e trabalho: Uma articulação indispensável. In J. E. Borges-Andrade, W. Codo \& A. Tamayo (Orgs.), Trabalho, organizações e cultura (pp. 21-26). São Paulo: Cooperativa de Autores Associados.

Jobert, G. (2014). O formador de adultos: Um agente de desenvolvimento. Cadernos de Psicologia Social do Trabalho, 17(1), 2132. doi:10.11606/issn.1981-0490.v17ispe1p21-32.

Lima, M. E. A. (2008). Trabalho e identidade: Uma reflexão à luz do debate sobre a centralidade do trabalho na sociedade contemporânea. Educação \& Tecnologia, 12, 5-9.

Marcelino, P., \& Cavalcante, S. (2012). Por uma definição de terceirização. Caderno CRH, 25(65), 331-346. doi:10.1590/s010349792012000200010.

Martinez, M. C., \& Latorre, M. R. D. O. (2008). Saúde e capacidade para o trabalho de eletricitários do Estado de São Paulo. Ciência \& Saúde Coletiva, 13(3), 1061-1073. doi:10.1590/s1413-81232008000300029.

Minella, J. (2013). Experiência e dialética histórica: Sua operação nas pesquisas de E.P. Thompson sobre os motins de fome na Inglaterra do século XVIII. Em Tese, 9(2), 62-81. doi:10.5007/1806-5023.2012v9n2p62.

Organista, J. H. C. (2006). O debate sobre a centralidade do trabalho. São Paulo: Expressão Popular.

Organização das Nações Unidas. (2009). Declaração Universal dos Direitos Humanos de 1948. Rio de Janeiro: Unic/Rio. Recuperado de http://www.onu.org.br/img/2014/09/DUDH.pdf

Palassi, M. P., \& Paula, A. P. P. (2014). Pesquisas sobre subjetividade nos estudos organizacionais: Complexidade e desafios de um enfoque histórico-cultural. In E. M. Souza (Org.), Metodologias e analíticas qualitativas em pesquisa organizacional: Uma abordagem teórico-conceitual (pp. 157-182). Vitória: EDUFES.

Pêcheux, M. (2002). O discurso: Estrutura ou acontecimento (3a ed.). Campinas: Pontes.

Saint-Martin, C. (2008). La normalization de la précarité dans les organizations professionaelles: De quoi parle-t-on? In G. Terssac, C. Saint-Martin \& C. Thebault (Coords.), La precarité: Une relation entre travail, organizatin e santé (pp. 1-4). Toulouse: Octarès Ed.

Thompson, E. (1981). A miséria da teoria ou um planetário de erros: Uma crítica ao pensamento de Althusser. Rio de Janeiro: Zahar Ed.

Ventura, M. M. (2007). O estudo de caso como modalidade de pesquisa. Revista da Sociedade de Cardiologia do Estado do Rio de Janeiro, 20(5), 383-386. 